\title{
POLÍTICAS PÚBLICAS PARA MULHERES ENCARCERADAS NO BRASIL: UM INSTRUMENTO GARANTIDOR DA DIGNIDADE
}

\section{PUBLIC POLICIES FOR WOMEN INCARRED IN BRAZIL: A GUARANTEE OF DIGNITY INSTRUMENT}

\begin{abstract}
PATRÍCIA VERÔNICA NUNES CARVALHO SOBRAL DE SOUZA Doutora em Educação pela UFS. Doutoranda em Direito Público pela UFBA. Mestre em Direito Público UFS. Professora titular de Direito Administrativo - UNIT. Diretora Técnica do Tribunal de Contas do Estado de Sergipe.E-mail: patncss@gmail.com.

\section{CLARA CARDOSO MACHADO JABORANDY}

Doutora e Mestre em Direito pela UFBA. Professora do Mestrado em Direitos Humanos da Universidade Tiradentes. Lider do grupo de pesquisa "Direitos Fundamentais, novos direitos e evolução social" presente no diretório do CNPQ. Email: claracardosomachado@gmail.com.
\end{abstract}

LIZIANE PAIXÃO S. OLIVEIRA Doutora em Direito pela Universidade Aix-Marseille III, na França (2012), Mestre em Direito pela Universidade de Brasília (2006). Professora do Programa de Mestrado e Doutorado em Direito do UniCEUB. Professora da Universidade Tiradentes. Bolsista de pós-graduação pela CAPES-FAPITEC (2017-2018). Pesquisadora do Instituto de Tecnologia e Pesquisa (ITP).

\section{RESUMO}

No Brasil, a situação de mulheres encarceradas ainda se encontra inserida em um panorama frágil em face da incipiência das políticas públicas. De acordo com o 
levantamento nacional de informações penitenciárias (INFOPEN Mulheres) produzido em 2017 é necessário considerar e garantir os direitos humanos destas mulheres e, para isso, se requer o aprimoramento de políticas que atendam às suas necessidades e tutelem seus direitos específicos. Nesse sentido, este ensaio tem por objetivo analisar os dados existentes neste último relatório com o intuito de verificar se há políticas públicas destinadas às mulheres encarceradas no Brasil e se a dignidade das mulheres presas está sendo observada. Para tanto utilizou-se dos métodos descritivo, exploratório, quali-quantitativo, bem como revisão bibliográfica. Inicialmente, o artigo demonstrou a situação da mulher encarcerada no Brasil. Logo após, abordou-se as políticas públicas necessárias à garantia dos direitos previstos no âmbito interno e internacional. Constatou-se ao final a necessidade de implementação de políticas públicas para as mulheres encarceradas com o intuito de diminuir o encarceramento provisório bem como instrumento garantidor da dignidade da mulher presa.

PALAVRAS-CHAVE: Dignidade da Pessoa Humana; Mulheres Encarceradas; Políticas Públicas.

\section{ABSTRACT}

In Brazil, the situation of imprisoned women is still framed in a fragile scenario in the face of the incipience of public policies. According to the national survey of penitentiary information (INFOPEN Women) produced in 2017, it is necessary to consider and guarantee the human rights of these women, and for that, it is necessary to improve policies that meet their needs and protect their specific rights. In this sense, the purpose of this essay is to analyze the data available in this last report in order to verify if there are public policies aimed at women incarcerated in Brazil and whether the dignity of women prisoners is being observed. For this purpose, descriptive, exploratory, qualitative and quantitative methods were used as well as bibliographic review. Initially, the article demonstrated the situation of women incarcerated in Brazil. Shortly afterwards, the public policies necessary to guarantee the rights foreseen in 
the internal and international scope were discussed. The need to implement public policies for incarcerated women with a view to reducing provisional incarceration as well as an instrument guaranteeing the dignity of women prisoners was confirmed.

KEYWORDS: Dignity of the Human Person; Incarcerated Women; Public Policy.

\section{INTRODUÇÃO}

O cárcere feminino no Brasil surgiu em meados do século XIX em casas de domínio religioso, definidas como "casas de depósito", com a finalidade de "domesticar" as mulheres. Esses locais recebiam não apenas mulheres sentenciadas, mas também esposas, filhas, irmãs e criadas de homens de classe média e alta que buscavam castigá-las ou admoestá-las (AGUIRRE, 2007, p. 51).

A partir da década de 1920, o Estado foi se responsabilizando pelas mulheres encarceradas. $O$ interesse tardio do poder público em relação às casas de detenção femininas decorre da conjuntura patriarcalista visualizada no Brasil em que a desigualdade de gênero é uma realidade cogente. Ainda persiste uma frágil ação dos poderes públicos em relação ao cárcere feminino, visto que são mínimas as políticas públicas voltadas à mulher encarcerada como sujeito de direitos, bem como a ausência de atenção quanto a questões de gênero.

Há, na realidade, uma incongruência no sistema penal entre o "superinvestimento em segurança pública" e a escassez de políticas sociais (estrutura e ressocialização) voltadas para atendimento dos direitos fundamentais dos presos e das presas. Especificamente em relação às mulheres encarceradas a situação é ainda mais alarmante já que segundo o Levantamento Nacional de Informações Penitenciárias - INFOPEN Mulheres (BRASIL, 2017) de 2000 a 2016 a taxa de aprisionamento de mulheres aumentou em $656 \%$ em relação ao total registrado no início dos anos 2000. No mesmo período, a população prisional masculina cresceu 293\%. Em junho de 2016 45\% das mulheres presas não haviam sido ainda julgadas 
e condenadas. Além disso, em geral, a população carcerária feminina, cumpre sentença média de oito anos.

O relatório informou ainda que as detentas são oriundas, na quase totalidade, de famílias de baixa renda, e exerciam atividades informais antes de sua prisão e vivenciaram um histórico de violência familiar, maternidade precoce, perda financeira e uso de drogas, entre outros fatos agravantes.

Por certo, diversos direitos das mulheres presas são violados pelo Estado Brasileiro, através da desatenção aos direitos essenciais como à saúde, educação, trabalho, política de reintegração social, e preservação de vínculos e relações familiares.

Nesse sentido, é cogente um investimento em políticas públicas penitenciárias voltadas às mulheres encarceradas, que efetivamente as ressocializem e as amparem como forma de garantia da dignidade das mesmas, bem como instrumento de fomento de reconhecimento da mulher pela própria comunidade e diminuição da exclusão social.

O presente estudo se justifica pela atualidade e inesgotabilidade da temática, tendo em vista o cenário que envolve a mulher na sociedade, minando-Ihe a dignidade humana, cerceando-lhe a liberdade, inutilizando-a desde tempos imemoriais e alcançando a dita civilização da tecnologia e da comunicação, da globalização e dos avanços científicos em todas as áreas do conhecimento humano. Trata-se de uma contribuição ao debate que apresenta claramente o seu valor acadêmico-científico e social, sob quaisquer prismas que sejam focados.

Este é um artigo de natureza qualitativa e exploratória, proporcionando ao pesquisador colher maiores informações sobre determinado assunto, além de maior familiaridade com o problema (GIL, 2009). A fragilidade da temática sobre políticas públicas penitenciárias para mulheres no Brasil é objeto de atenção de diversos estudos, em especial, no campo criminológico. Nada obstante, além da investigação sobre a execução dessas políticas, deve ser considerada a perspectiva dos direitos humanos e do reconhecimento da dignidade das mulheres.

Para tanto, partiu-se da demonstração do contexto da mulher encarcerada no Brasil a partir do levantamento Nacional de Informações Penitenciárias - INFOPEN 
Mulheres referentes a junho de 2016. Para ao final concluir pela necessidade de políticas públicas voltadas para as mulheres encarceradas com o escopo de se respeitar o princípio da dignidade humana.

\section{A MULHER ENCARCERADA NO BRASIL}

O Levantamento Nacional de Informações Penitenciárias - INFOPEN Mulheres referentes a junho de 2016 (BRASIL, 2018), atestou que a população prisional feminina atingiu a marca de 42 mil mulheres privadas de liberdade, representando um aumento de $656 \%$ em relação ao total registrado no início dos anos 2000, quando menos de 6 mil mulheres se encontravam no sistema prisional. No mesmo período a população prisional masculina cresceu $293 \%$, revelando a curva ascendente do encarceramento da massa feminina.

As mulheres em cárcere, via de regra, têm filhos, são jovens, são as provedoras do sustento familiar e têm pouca escolaridade. Em média, $68 \%$ dessas mulheres possuem apontamento penal por envolvimento com o tráfico de drogas, em que a maioria ocupa a posição coadjuvante no crime, atuando no transporte de drogas e pequeno comércio, vulgarmente denominadas de "mulas do tráfico" (SOARES; ILGENFRITZ, 2002).

Quanto aos estabelecimentos prisionais, observa-se que a maior parte dos estabelecimentos prisionais foi projetada para o público masculino totalizando um percentual de 74\% (INFOPEN, 2018, p.22), enquanto apenas 7\% é destinada ao público feminino e $16 \%$ é caracterizado como misto, já que possui ala específica para aprisionamento de mulheres em um estabelecimento originariamente masculino. Desse contexto estatístico conclui-se que a maior parte das mulheres estão em unidades mistas, o que ressalta a inadequação de encarceramento feminino e pontua a real e urgente necessidade de implementação de políticas públicas para minimizar a situação atual e garantir o respeito à Constituição.

No tocante à garantia de direitos, o relatório aponta dados alarmantes como por exemplo a verificação de que apenas $34 \%$ dos estabelecimentos contam com 
espaços destinados à implementação do direito a receber visita do cônjuge, da companheira, de parentes e amigos (INFOPEN Mulheres, 2018, p.24). Em relação ao exercício do direito à visita íntima, com observância à dignidade e privacidade da pessoa presa, verifica-se que em relação às unidades femininas, $41 \%$ dos estabelecimentos contam com local específico e, no caso dos estabelecimentos mistos, apenas $34 \%$ das unidades podem oferecer este espaço, fato que demonstra que a grave violação à dignidade da mulher e ao direito de privacidade, decorrente de uma limitação estrutural (INFOPEN Mulheres, 2018, p.26).

Em relação à infraestrutura relativa à maternidade no interior dos estabelecimentos prisionais, constatou-se que nos presídios femininos ou mistos que $16 \%$ dispõem de cela ou dormitório adequado para gestantes, 14\% dispõem de berçário ou centro de referência materno infantil que compreendem os espaços destinados a crianças com até 2 anos de idade e apenas 3\% dispõem de creche (INFOPEN Mulheres, 2018).

Esses números são inquietantes e revelam uma violação generalizada aos direitos humanos das mulheres encarceradas indo de encontro ao compromisso feito pelo Brasil no âmbito da Organização das Nações Unidas com o cuidado com a saúde maternal, Objetivo de Desenvolvimento do Milênio n. 5, bem como o objetivo do desenvolvimento sustentável n. 5 de alcançar a igualdade de gênero e empoderar todas as mulheres e meninas. Vislumbra-se ainda a não observância do compromisso internacional assumido pelo Brasil em relação às Regras das Nações Unidas para o Tratamento de Mulheres Presas e Medidas Não Privativas de Liberdade para Mulheres Infratoras, também conhecidas como Regras de Bangkok¹.

\footnotetext{
${ }^{1}$ Dentre as regras destacam-se: 6.23.1. Nos estabelecimentos penitenciários para mulheres devem existir instalações especiais para o tratamento das reclusas grávidas, das que tenham acabado de dar à luz e das convalescentes. Desde que seja possível, devem ser tomadas medidas para que o parto tenha lugar num hospital civil. Se a criança nascer num estabelecimento penitenciário, tal fato não deve constar do respectivo registro de nascimento. 6.23.2. Quando for permitido às mães reclusas conservar os filhos consigo, devem ser tomadas medidas para organizar um berçário dotado de pessoal qualificado, onde as crianças possam permanecer quando não estejam ao cuidado das mães. 6.b.10. Serão oferecidos às presas serviços de atendimento médico voltados especificamente para mulheres, no mínimo equivalentes àqueles disponíveis na comunidade. 7.c.24. Instrumentos de contenção jamais deverão ser usados em mulheres em trabalho de parto, durante o parto e nem no período imediatamente posterior. 56. As autoridades competentes reconhecerão o risco específico de abuso que enfrentam as mulheres em prisão cautelar e adotarão medidas adequadas, de caráter normativo e
} 
$\mathrm{Na}$ verdade, além da grave violação a direitos humanos tem-se um desrespeito à Constituição Federal que estabelece os direitos fundamentais da mulher encarcerada como também à lei 11.942/2009, que promoveu mudanças na lei de execução penal para prever a proteção à saúde maternal.

Normalmente, têm-se as expressões "direitos humanos" e "direitos fundamentais" aplicadas como sinônimas. Necessário se faz distingui-las. Os direitos humanos são os direitos válidos e abrangem todos os povos e todos os tempos (dimensão jusnaturalista/universalista), já os direitos fundamentais são os direitos do homem, jurídico-institucionalmente assegurados e limitados espaço-temporalmente (CANOTILHO, 2003).

Dessa forma, pode-se afirmar que "direitos humanos" correspondem aos direitos inerentes a todo e qualquer ser humano no cenário do Direito Internacional, enquanto os "direitos fundamentais" correspondem àqueles recepcionados e assegurados pelo ordenamento jurídico interno de um Estado.

Para Joaquín Herrera Flores (2009, p.191) considera os direitos humanos:

[...] como produtos culturais que formam parte da tendência humana ancestral por construir e assegurar as condições sociais, políticas, econômicas e culturais que permitem aos seres humanos perseverar na luta pela dignidade, ou, o que é o mesmo, o impulso vital que, em termos spinozianos, Ihes

prático, para garantir sua segurança nessa situação. 57. As provisões das Regras de Tóquio deverão orientar o desenvolvimento e a implementação de respostas adequadas às mulheres infratoras. Deverão ser desenvolvidas, dentro do sistema jurídico do Estado membro, opções específicas para mulheres de medidas despenalizadoras e alternativas à prisão e à prisão cautelar, considerando o histórico de vitimização de diversas mulheres infratoras e suas responsabilidades de cuidado. 58 . Considerando as provisões da regra 2.3 das Regras de Tóquio, mulheres infratoras não deverão ser separadas de suas famílias e comunidades sem que se considere devidamente a sua história e laços familiares. Formas alternativas de lidar com mulheres infratoras, tais como medidas despenalizadoras e alternativas à prisão, inclusive à prisão cautelar, deverão ser empregadas sempre que apropriado e possível. 59. Em geral, serão utilizadas medidas protetivas não privativas de liberdade, como albergues administrados por órgãos independentes, organizações não governamentais ou outros serviços comunitários, para assegurar proteção às mulheres que necessitem. Serão aplicadas medidas temporárias de privação da liberdade para proteger uma mulher unicamente quando seja necessário e expressamente solicitado pela mulher interessada, sempre sob controle judicial ou de outras autoridades competentes. Tais medidas de proteção não deverão persistir contra a vontade da mulher interessada. (Regras de Bangkok: Regras das Nações Unidas para o Tratamento de Mulheres Presas e Medidas Não Privativas de Liberdade para Mulheres Infratoras/ Conselho Nacional de Justiça, Departamento de Monitoramento e Fiscalização do Sistema Carcerário e do Sistema de Execução de Medidas Socioeducativas, Conselho Nacional de Justiça - 1. Ed - Brasília: Conselho Nacional de Justiça, 2016). 
possibilita manter-se na luta por seguir sendo o que são: seres dotados de capacidade e potência para atuar por si mesmos [...].

A Constituição Federal de 1988 adotou os princípios trazidos pela Declaração de Direitos Humanos de 1948 e os ampliou através da delimitação dos direitos e das garantias fundamentais (Título II, da CF/88), que estão sistematizados no Texto Constitucional além de outros direitos e garantias oriundos do regime e dos princípios adotados pela Constituição Federal, ou de tratados internacionais dos quais o Brasil faça parte (art. $5^{\circ}, \S^{\circ}$ da CF/88).

No ordenamento jurídico brasileiro, o artigo 5ำ I, da CF/88, preceitua que "homens e mulheres são iguais em direitos e obrigações". Essa interpretação ocasiona a intolerância da utilização do discrímen sexo, no momento intencional de descriminar materialmente o homem e a mulher, somente sendo cabível quando a intenção for apontar desníveis. Nesse sentido, a legislação infraconstitucional estabelece e elabora formas de tratamentos diferenciados para homens e mulheres no momento em que a finalidade for assegurar e proteger os direitos de ambos, apontando as diferenças entre eles.

Com efeito, a mulher distingue-se do homem física e psicologicamente e, tal condição natural requer a aplicação de tratamentos distintos, porém, esta distinção não pode ser ilegítima, mas sim, através de tratamentos especiais exigidos pela própria condição fisiológica e psíquica da mulher, para que esta possa conviver em grau de igualdade perante o homem. Trata-se de discriminação positiva preconizada por Celso Antonio Bandeira de Melo (2008).

Em relação às espécies de tratamentos relativos às mulheres insertas em situação de cárcere, constata-se que o Estado brasileiro não tem garantido condições adequadas para o cumprimento da pena privativa de liberdade e, consequentemente, da ressocialização, em consonância com o ordenamento jurídico vigente.

O INFOPEN Mulheres demonstra diversas condições degradantes e desumanas vivenciadas pelas mulheres encarceradas no Brasil a exemplo de unidades prisionais inadequadas (em alguns locais as mulheres são mantidas com homens); insalubridade das instalações prisionais; ausência de assistência à saúde 
adequada, em especial, durante a gestação e após o parto; inadequação do local físico para acolher o recém-nascido; desrespeito ao período de permanência das mães com seus filhos e falta de investimento em educação e cultura nos presídios.

No Estado Brasileiro a sanção penal tem três finalidades: retributiva, preventiva - geral e especial - e ressocializadora ou reeducativa (art. $1^{\circ}$ e $10^{\circ}$ da LEP). Dentre elas, ressalta-se o caráter reeducativo da pena, preceituado também pelo art. 22 da mesma Lei: "[...] a assistência social tem por finalidade amparar o preso e o internado e prepará-los para o retorno a liberdade".

Nesse sentido, para Beccaria (2009, p. 56):

Fica evidente que o fim das penas não é atormentar e afligir um ser sensível, nem desfazer o delito já cometido [...] O fim da pena, pois é apenas o de impedir que o réu cause novos danos aos seus concidadãos e demover os outros de agir desse modo. É necessário selecionar quais penas e quais os modos de aplicá-las, de tal modo que, conservadas as proporções, cause impressão mais eficaz e mais duradoura no espírito dos homens, e a menos tormentosa no corpo do réu.

Não obstante, as circunstâncias de encarceramento em que vivem as mulheres requerem do Estado uma atuação proativa e tratamento especializado, em prol da efetivação dos direitos e das garantias fundamentais e da observância do compromisso internacional. Em decorrência da natureza intrínseca a mulher, a mãe detenta sofre com a ausência dos filhos, bem mais do que o homem, resultante da própria fisiologia materna (gestação), por exemplo. (MAKKI , 2017).

Porquanto, para garantir a efetividade dos direitos das mulheres encarceradas, a Constituição Federal e legislação penal extravagante estabelecem direitos e garantias essenciais à mulher encarcerada, dentre eles: a possibilidade de permanecerem com seus filhos durante o período de amamentação (art. 5ㅜ, L da CF/88); a existência de berçários nas Unidades Prisionais (art. 83, § 2ํ da LEP); 0 ensino educacional adequado à sua condição (art. 19, parágrafo único da LEP); o direito de serem recolhidas em estabelecimento prisional próprio e adequado a sua condição (art. 82, $\S 1^{\circ}$ da LEP); a possibilidade de existir na Unidade Prisional uma 
seção para gestante, e creche para assistir o menor desamparado cuja mãe esteja presa (art. 89 da LEP).

Apesar da positivação destes direitos os dados estatísticos demonstram que há um grande distanciamento do texto e contexto, já que a maioria das unidades prisionais não observa essas determinações constitucionais e infraconstitucionais, fato que denota uma violação generalizada aos direitos das mulheres encarceradas.

Não bastasse todas as falhas estruturais no sistema penitenciário brasileiro, há ainda uma cultura pelo encarceramento, vislumbrada pela imposição de prisões provisórias a mulheres pobres e vulneráveis, decorrente, muitas vezes, de um proceder mecânico e acrítico do Poder Judiciário que sente a necessidade de dar uma resposta ao clamor público do uma sociedade punitivista e individualista. O resultado disso é o desrespeito contínuo à dignidade das mulheres submetidas a uma situação carcerária degradante.

A fim de rebater a cultura do encarceramento e resguardar o princípio da proteção integral da criança, o Estatuto da Primeira Infância (lei 13.257/16) garantiu prisão domiciliar a mulheres grávidas ou com crianças de até 12 anos. Para atender essa determinação em 20 de fevereiro de 2018 a $2^{\text {a }}$ turma do STF concedeu, por maioria, habeas corpus coletivo (HC 143641/SP) a todas as presas grávidas e mães de crianças de até 12 anos de idade ou que sejam responsáveis por pessoas com deficiência, assim como às adolescentes do sistema socioeducativo em situação semelhante.

O referido Habeas Corpus determinou a substituição da prisão preventiva pela domiciliar a todas as mulheres nestas condições, com exceção daquelas que tenham cometido crimes mediante violência ou grave ameaça, contra os próprios filhos, ou, ainda, em situações excepcionalíssimas — casos em que o juiz terá de fundamentar a negativa e informar ao Supremo a decisão.

Esta decisão representa um avanço e é plenamente condizente com a determinação constitucional bem como com os textos normativos que integram o patrimônio mundial de salvaguarda das mulheres encarceradas, em especial com as regras de Bangkok, que determina que se priorize soluções judiciais que facilitem a 
utilização de alternativas penais ao encarceramento, principalmente para as hipóteses em que ainda não haja decisão com trânsito em julgado.

Para além dessa decisão do Supremo Tribunal Federal é mister impulsionar a criação de políticas públicas preventivas para diminuir o encarceramento provisório feminino bem como forma de garantir a dignidade das mulheres encarceradas.

\section{A IMPORTÂNCIA DAS POLÍTICAS PÚBLICAS PARA AS MULHERES}

Não restam dúvidas de que a Constituição Federal de 1988 foi progressista ao superar a ótica assistencialista direcionada para as políticas públicas ou programas sociais no momento em que intuiu a máxima potencialização dos direitos fundamentais da pessoa, em especial, os direitos sociais, em prol da concretização da cidadania de toda a sociedade, neste caso, incluindo a cidadania feminina plena, ao estabelecer como premissa básica que homens e mulheres são iguais em direitos e obrigações nos moldes do art. $5^{\circ}$ da $\mathrm{CF} / 88$.

A Constituição Federal, diante do processo democrático que vem se robustecendo no Brasil, que pressupõe como indispensável a inclusão da sociedade civil no combate aos seus percalços sociais, aponta que toda a coletividade deve estar unida em prol da conquista de uma sociedade mais justa, livre e solidária. Nesse sentido, o Estado deve atuar quebrando as antigas práticas clientelistas, sem influir nas políticas públicas direcionadas a efetividade dos direitos básicos das mulheres.

De certo, o fortalecimento do movimento feminista surgiu no Brasil a partir de 1970 e após uma década se fortaleceu, verificou-se um grande movimento feminista também na área acadêmica, que resultou na tentativa de integração da concepção de gênero nas políticas públicas e programas governamentais, para estabelecer pautas políticas relativas às mulheres (FARAH, 2004).

Cabe ressaltar, a definição de gênero se estrutura a partir da ênfase nas relações sociais, políticas, econômicas e culturais, entre outras, presentes entre os sexos, visto que aponta as condições de desigualdades presentes entre homens e 
mulheres, em especial, aquelas relativas às relações hierárquicas e de poder (SCOTT, 1995).

Existem outras desigualdades vinculadas, além de raça e etnia, classe, geração etc., tais como de acesso a outras espécies da esfera pública, isto é, à justiça, à tecnologia, à saúde, ao sistema financeiro, dentre outros. Dessa forma, imperioso se faz elaborar políticas públicas "de gênero" no sentido de se concretizar a condição emancipatória e fomentar a independência e autonomia feminina, com vistas a alcançar as mudanças que se pretende.

Ainda é oportuno distinguir as políticas que têm o objetivo de igualdade de gênero e as políticas que têm por alvo as mulheres, porém, não se pode olvidar que tais políticas estejam correlacionadas. Não se pode negar que a definição de gênero apenas fortaleceu-se como método de pesquisa de questões sociais das mulheres. No entanto, o conceito de gênero é utilizado para diferenciar e descrever as categorias de mulher e de homem, bem como para analisar as relações de desigualdades e de poder estabelecidas entre os sexos e identificar as relações desiguais intragênero presentes entre as mulheres, seja de condição socioeconômica, racial, étnica, religiosa, regional etc.

Por conseguinte, na política de gênero analisa-se a lógica de políticas públicas de acordo com influência do impacto diferenciado entre homens e mulheres. Esse raciocínio não se contradiz ao reconhecimento, legitimidade e a importância das ações voltadas para o fortalecimento das mulheres que ainda se encontram em posição desigual e de submissão na sociedade. A implantação de políticas públicas, assim, é vital para a elaboração e fortalecimento da cidadania das mulheres e a igualdade nas relações de gênero (RODRIGUES, 2017).

Para dirimir tais desigualdades de gênero, presentes no sistema das desigualdades sócio históricas e culturais enraizadas, o Estado deve reconhecer a existência de políticas públicas distintas de gêneros e implantar ações diferenciadas direcionadas às mulheres. (SILVANA, 2003)

$\mathrm{Na}$ esfera federal, as ações são efetivadas pela Secretaria de Políticas para as Mulheres e, resultam do processo de mobilização das próprias mulheres, por meio de suas ramificações, com consequências nas instâncias municipais, estaduais e 
nacional. As políticas públicas, neste aspecto, são direcionadas pelo Plano Nacional de Políticas para as Mulheres (PNPM), desdobradas pelos organismos governamentais de políticas para as mulheres - estaduais e 4 municipais e estes têm por finalidade definir os agentes femininos, através do ativismo político das mulheres organizadas, para assegurar políticas públicas de gênero, independente da descaracterização das fragilidades oriundas da ausência de uma análise nacional mais eficiente, bem como através da consideração da insistência das funções tradicionais da mulher, no recinto doméstico, que formam a divisão sexual do trabalho, no desempenho das ações de esposas, mães, dentre outros.

Diante dessa circunstância, devem ser elaborados novos métodos e estruturas de articulação entre a vida familiar e a vida pública, em prol do rompimento da tradicional divisão sexual do trabalho.

A divisão das funções dos gêneros feminino e masculino insere-se no senso comum como forma de família normal e heteronormativa, onde os homens são considerados provedores e as mulheres as responsáveis pelo recinto doméstico. É latente que essa estrutura familiar tradicional e conservadora vêm cada vez mais dividindo espaço com outras modalidades familiares, tanto em relação aos diversos conjuntos familiares existentes, quanto à manutenção econômica das famílias monoparentais, onde as mulheres figuram como responsáveis pelo monopólio familiar.

As desigualdades de gênero referem-se a diversos aspectos distintivos entre homens e mulheres, entre eles $\mathrm{o}$ acesso aos bens sociais e aos programas de geração de renda, de inserção no mercado de trabalho, nos sistemas de tecnologias e informática, os quais asseguram o acesso às várias dimensões da cidadania.

Percebe-se que a essa categoria de gênero correlacionam-se diversos aspectos institucionais em relação às políticas públicas, atuando em prol da inclusão de uma nova linguagem, bem como nas distinções, no uso e sentido vinculado a definição de gênero.

As políticas públicas não devem ser neutras. Entretanto, devem promover a construção de meios de discussão, debates, com a finalidade de definir prioridades e construir estratégias para elaborar e modificar os organismos de políticas para 
mulheres nos governos em suas esferas federal, estadual e municipal, isto é, deve e pode se construir uma nova institucionalidade, no momento que se analise o benefício que esta elaboração ocasionará. Dessa forma, políticas integradas de gênero contribuem para a criação e o desenvolvimento de organismos de políticas públicas para mulheres.

Destarte, a construção de políticas públicas de igualdade para as mulheres tornam o Estado mais participativo, centrado na mobilização social, bem como em um Estado democrático, este último com a função precípua de elaborar políticas que reconheçam as desigualdades econômicas e políticas entre homens e mulheres, sobretudo, as encarceradas.

\section{A GARANTIA DA DIGNIDADE DA MULHER PRESA}

É de se destacar que a dignidade da mulher remete ao princípio máximo da Carta Magna, qual seja, o princípio da dignidade da pessoa humana que está diretamente vinculado a efetivação dos direitos fundamentais. Outrossim, é impossível falar em direitos como, à vida, à liberdade, à igualdade, sem garantir a dignidade dos possuidores destes direitos.

Sabe-se que o princípio constitucional retro mencionado é visto como uma positivação material, uma vez que é inerente a condição humana a sua natureza racional em que a lei prevê sua inviolabilidade e a obrigação de todo o poder estatal em respeitá-la e protegê-la. Acerca desse entendimento, Soares preleciona que:

A dignidade da pessoa humana figura como o primeiro fundamento de todo o sistema constitucional posto e o último arcabouço da guarida dos direitos fundamentais, porquanto a busca pela realização de uma vida digna direciona o intérprete do direito à necessária concretização daqueles valores essenciais a uma existência digna. (SOARES, 2010a, p. 146).

Sem embargo, mesmo diante da dificuldade de materializar a definição da dignidade da pessoa humana, pode-se aferir que o respeito a essa premissa é um meio de alcançar e efetivar as normas legais e o acesso à real justiça, à proteção do 
bem da vida e do reconhecimento da natureza humana, de sua racionalidade e autonomia. Ao buscar definir a dignidade da pessoa humana, Sarlet identifica a dificuldade em conceituá-la:

Dignidade Humana é a qualidade intrínseca e distintiva reconhecida em cada ser humano que o faz merecedor do mesmo respeito e consideração por parte do Estado e da comunidade, implicando, neste sentido, um complexo de direitos e deveres fundamentais que assegurem a pessoa tanto contra todo e qualquer ato de cunho degradante e desumano, como venham a lhe garantir as condições existenciais mínimas para uma vida saudável, além de propiciar e promover sua participação ativa e co-responsável nos destinos da própria existência e da vida em comunhão com os demais seres humanos, mediante 0 devido respeito aos demais seres que integram a rede da vida. (SARLET, 2007, p.63).

No mesmo passo, Canotilho (2000, p. 225-226) conceitua a dignidade humana como um princípio antrópico, que adota a ideia pré-moderna e moderna da dignitas-hominis, isto é, do indivíduo conformador de si próprio e de sua vida segundo o seu próprio projeto espiritual. Para ele, ainda existe a lembrança da experiência aniquiladora do homem (nazismo, escravidão, genocídios, etc.), o que significa dizer que a dignidade é o reconhecimento do homo noumenon, o sujeito é entendido como o fundamento e limite da república.

Nessa toada, a atividade estatal deve ter como premissa o valor da dignidade humana, expandida a todo o ordenamento jurídico, como fundamento do Estado Democrático de Direito (art.1ํㅡㄹ III da CF/88), ao lado de outros princípios igualmente relevantes, como: o republicano, a separação de poderes, entre outros (SOARES, 2003).

Nesta visão, pontua-se o desafio de articular políticas públicas para toda a população presidiária, que vem aumentando em escala. $O$ aumento do encarceramento feminino é um fenômeno que tem crescido muito no Brasil. No relatório INFOPEN Mulheres (2018) constatou-se que o Brasil encontra-se na quarta posição mundial entre os países que mais encarceram mulheres no mundo, ficando atrás apenas dos Estados Unidos, da China e da Rússia em relação ao tamanho absoluto de sua população prisional feminina. 
Não bastasse isso, o sistema penitenciário brasileiro é internacionalmente conhecido como violador dos direitos da dignidade das pessoas encarceradas, em especial, em relação aos direitos da dignidade das mulheres presas, que não possuem suas demandas supridas e, além das violações aos seus direitos de forma geral, ainda têm desrespeitados seus direitos sexuais e reprodutivos, bem como o não cumprimento de suas necessidades básicas, entre elas, a de vestuário, acesso à saúde especializada, necessidades familiares e psíquicas.

Nessa compreensão, fatos relacionados à pobreza e igualdade são pontos principais nos objetivos das políticas públicas. Porém, entender políticas públicas enquanto legitimidade na esfera do Estado é uma especialidade relativa às questões de caráter público, caso respeitadas as individualidades e a apoderação de indivíduos.

Portanto, persiste, ainda, politicas públicas ineficientes para a efetivação dos direitos humanos por parte do Estado, considerando que estes correspondem à dignidade da pessoa humana. (SOARES, 2010b). O princípio da dignidade da pessoa humana, como fundamento para o ordenamento jurídico, serve para vincular os poderes públicos à sua efetivação, de forma programática e também concreta.

Em consonância com este entendimento, a Ministra Carmen Lúcia Rocha preleciona que "[...] o princípio da dignidade da pessoa humana entranhou-se no constitucionalismo contemporâneo, daí partindo e fazendo-se valer em todos os ramos do Direito" (ROCHA, 1999, p. 23-49). E complementa asseverando que o princípio da dignidade da pessoa humana possui forte importância para a construção de políticas públicas.

No que concerne à política penitenciária, relacionada às políticas públicas direcionadas à execução penal, estabelecimentos prisionais, práticas voltadas à reintegração social, apoio ao egresso, entre outros, o órgão competente por esse setor da Administração Pública é o Conselho Nacional de Política Criminal e Penitenciária. Nesse sentido, a política penitenciária é uma espécie de política pública aplicada ao setor de segurança pública e execução criminal, relativa às questões definidas como de aspecto público e também, relativo às questões que envolvem mulheres presas.

Destarte, as políticas penitenciárias relativas às mulheres presas necessitam estar em conformidade com a dignidade da pessoa humana, visando assegurar 
direitos mínimos de sobrevivência e reconhecimento. Além das questões gerais que envolvem o sistema prisional, como exclusão, marginalização socioeconômica e cultural, bem como a estigmatização da população negra e pobre. Outras particularidades em matérias de direitos humanos colocam as mulheres em diversas situações de vulnerabilidade, seja em relação aos filhos, ao lapso temporal da gestação, subsistência material da família, autonomia do corpo e liberdade para exercício reprodutivo e sexual.

É mister criar políticas públicas voltadas especificamente para as mulheres encarceradas, tutelando-se direitos sociais das mulheres na prisão com o recurso das políticas sociais.

Diante dessa realidade, as políticas públicas voltadas para o sistema prisional feminino no Brasil revelam que há uma urgência pela efetivação de ações que visem a garantia de direitos fundamentais das mulheres encarceradas, resguardada pela dignidade da pessoa humana, fundamento básico de um Estado Democrático de Direito. Assim, necessário se faz a institucionalização, nos estados e nos municípios, de instâncias governamentais - secretarias, coordenadorias de políticas para as mulheres voltadas a essas políticas, com a finalidade de minimizar as desigualdades entre homens e mulheres.

O primeiro dos desafios para as políticas públicas é superar os limites dos programas e projetos nas óticas em que fortalecem o caráter tradicionalista das mulheres e não contribuem para sua autonomia, devendo se levar em conta a diversidade das mulheres e reconhecer que é relevante atender às necessidades inerentes a este gênero.

É preciso priorizar as creches e escolas públicas em período integral; programas de saúde contínuos; dispor de moradia digna; restaurantes populares; atividades de lazer e culturais, elaboração de redes de economia solidária redimensionando o exercício das mulheres nos denominados programas de geração de renda, acesso das mulheres aos recursos financeiros, ao acesso à propriedade da terra e, em cada uma das referidas ações, deve-se pontuar as categorias destas mulheres: negras, trabalhadoras rurais, trabalhadoras urbanas, mulheres lésbicas, mulheres jovens, mulheres idosas, dentre outras. 
Recomenda-se que estas políticas tenham a posição estratégica de ampliar a visibilidade, a participação social e a representação das mulheres, enaltecendo suas possibilidades e suas decisões, bem como aumentando o controle social sobre as políticas públicas.

Oportuno acrescentar que ações contra a prática de racismo e todas as manifestações de preconceito são importantes e indispensáveis para a construção da igualdade entre mulheres e homens. Os indicadores, por sua vez, mesmo sendo um novo desafio, podem evidenciar se há mudanças na distinção sexual do trabalho doméstico, se as mulheres jovens e as meninas da família deixaram de ser responsáveis pelo trabalho doméstico e pelo cuidado dos irmãos menores, bem como se existe a diminuição ou não da violência doméstica, se a formação e capacitação profissional das mulheres possibilitam acesso ao trabalho, entre outras informações.

\section{CONCLUSÃO}

Do ensaio apresentado pode-se inferir que para fortalecer e concretizar o projeto democrático desenhado pela Constituição Federal de 1988, faz-se cogente superar diversos desafios persistentes quanto a desigualdade de gênero e as disfunções de um sistema penitenciário que tem se mostrado falível em suas finalidades.

Os desafios são complexos para os gestores públicos e para o Judiciário e brasileiro, que contém robustas matrizes do patrimonialismo, da submissão e da exclusão social, resultando num sistema organizacional de estabelecimentos penais violadores de direitos das pessoas privadas de liberdade.

Nesta conjuntura, o tema do encarceramento feminino merece destaque. Os dados divulgados pelo Levantamento Nacional de Informações Penitenciárias referentes a dezembro/junho de 2016, buscam contribuir para sanar a lacuna relativa à disponibilidade de acesso a dados penitenciários por gênero que possam servir como baliza para a análise de implementação de políticas voltadas à superação das questões. 
Conforme os dados publicados oficialmente, comumente, as mulheres submetidas ao cárcere são jovens, têm filhos, possuem baixa escolaridade, são advindas de ambiente social economicamente pobre, são as mantenedoras da renda familiar e exercem, via de regra, atividades de trabalho informal anteriormente a reclusão.

As mulheres encarceradas trazem consigo necessidades e peculiaridades, resultados do seu histórico, como violência familiar, maternidade precoce, nacionalidade, perda financeira, uso de drogas, entre outras questões. Efetivamente, os meios e vínculos que as mulheres estabelecem em suas relações familiares, bem como o envolvimento com o crime, são distintos em comparação com a realidade dos homens privados de liberdade.

Diante disto é necessário que o Estado volte o olhar para esta realidade específica por meio de políticas públicas que garantam às mulheres encarceradas o respeito à sua dignidade. Urge, outrossim, investimento em políticas públicas preventivas para diminuição do encarceramento provisório feminino, principalmente para as situações da mulher que é mãe, impedindo-se o fenômeno das "crianças encarceradas".

Pensando nessa realidade a ação dialógica e conjunta dos poderes públicos é medida que se impõe, revelando-se necessária a concessão pelo Supremo Tribunal Federal de habeas corpus coletivo (HC 143641/SP) a todas as presas grávidas e mães de crianças de até 12 anos de idade ou que sejam responsáveis por pessoas com deficiência, assim como às adolescentes do sistema socioeducativo em situação semelhante.

Ademais, falar do sistema carcerário feminino é demonstrar a discriminação de gênero, possibilitando entender que o sistema judiciário e o sistema penitenciário brasileiros ainda estão presentes na reprodução hostil de gênero. Por fim, as ações integrantes das políticas públicas voltadas para mulheres devem ser efetivadas, visto que a integridade psicofísica das mulheres encarceradas deve ser assegurada, através de políticas públicas eficazes, como objetivo precípuo do Estado. 


\section{REFERÊNCIAS}

AGUIRRE, Carlos. O cárcere na América Latina, 1800-1940. In: MAIA, Clarissa Nunes et al. História das prisões no Brasil. Rio de Janeiro: Rocco, 2009, p. 35 a 70, v. 1.

BITENCOURT, Cezar Roberto. Falência da pena de prisão: causas e alternativas.3.ed. São Paulo: Saraiva, 2004.

ALMEIDA, Tânia Mara C. de e BANDEIRA. Lourdes. Políticas públicas destinadas ao combate da violência contra as mulheres - por uma perspectiva feminista, de gênero e de direitos humanos. In: BANDEIRA, Lourdes; ALMEIDA, Tânia Mara et. Ali. (ogs.). Violência contra as mulheres: a experiência de capacitação das DEAMs da Região Centro-Oeste. Brasília, Cadernos AGENDE, No. 5, dez/2004.

BECCARIA, Cesare. Dos Delitos e das Penas. Tradução de J. Cretella Jr. e Agnes Cretella. 4ํe ed. - São Paulo: Revista dos Tribunais, 2009, p.56.

BRASIL. Constituição da República Federativa do Brasil (1988). Promulgada em 05 de outubro de 1988.2 Disponível em: <http://www.planalto.gov.br/ccivil_03/constituicao/constituicaocompilado.htm>. Acesso em: 05 abr. 2017.

. Lei de Execução Penal. Lei no 7.210, Promulgada em 11 de Julho de 1984. Disponível em: <http:// http://www.planalto.gov.br/ccivil_03/leis/L7210.htm>. Acesso em: 08 abr. 2017.

Levantamento Nacional de Informações Penitenciárias. Ministério da Justiça. Departamento Penitenciário Nacional. Brasília: 2018. Disponível em: http://depen.gov.br/DEPEN/depen/sisdepen/infopenmulheres/infopenmulheres_arte_07-03-18.pdf. Acesso em 14 jul. 2018.

Levantamento Nacional de Informações Penitenciárias. Ministério da Justiça. Departamento Penitenciário Nacional. Brasília: 2014a. Disponível em: <http:// http://www.justica.gov.br/noticias/estudo-traca-perfil-da-populacao-penitenciariafeminina-no-brasil/relatorio-infopen-mulheres.pdf >. Acesso em: 06 abr. 2017.

Levantamento Nacional de Informações Penitenciárias. Ministério da Justiça. Departamento Penitenciário Nacional. Brasília: 2014b. Disponível em: <http:// http:// http://www.justica.gov.br/seus-direitos/politicapenal/documentos/infopen_dez14.pdf>. Acesso em: 07 abr. 2017.

Regras de Bangkok: Regras das Nações Unidas para o Tratamento de Mulheres Presas e Medidas Não Privativas de Liberdade para Mulheres Infratoras/ Conselho Nacional de Justiça, Departamento de Monitoramento e Fiscalização do Sistema Carcerário e do Sistema de Execução de Medidas Socioeducativas, Conselho Nacional de Justiça - 1. Ed - Brasília: Conselho Nacional de Justiça, 2016 
CANOTILHO, J. J. Gomes. Direito Constitucional e Teoria da Constituição, $7^{\circ}$ ed., 8ํㅡㄹ. Coimbra-Portugal. Ed. Almedina, 2003.

CUNHA JÚNIOR. Dirley da. Neoconstitucionalismo e o novo paradigma do Estado Constitucional de Direito: um suporte axiológico para a efetividade dos Direitos Fundamentais Sociais. In: CUNHA JÚNIOR, Dirley da; PAMPLONA FILHO, Rodolfo (organizadores). Temas de Teoria da Constituição e Direitos Fundamentais. Salvador: Podivm. 2007.

DELGADO, Maria do Carmo Godinho. Estrutura de Governo e Ação Política Feminista: A experiência do PT na Prefeitura de São Paulo. 2007. 258 f. Tese (Doutorado em Ciências Sociais) - Pontifícia Universidade Católica de São Paulo: São Paulo, 2007.

FARAH, Marta Ferreira Santos. Gênero e Políticas Publicas. Escola de Administração de Empresas de São Paulo da Fundação Getulio Vargas. Estudos Feministas. Florianópolis, 12 (1): 47-71, jan./abr. 2004.

FLORES. Joaquín Herrera. Teoria Crítica dos Direitos Humanos: Os Direitos Humanos como Produtos Culturais. Rio de Janeiro: Lumen Juris. 2009.

MAKKI, Salma Hussein. SANTOS, Marcelo Loeblein dos. Gênero e criminalidade: Um olhar sobre a mulher encarcerada no Brasil. Âmbito Jurídico, Rio Grande, 78, 01 jul/ $2010 . \quad$ Disponível em: <http://www.ambitojuridico.com.br/site/index.php?n_link=revista_artigos_leitura\&artigo_id=8080>. Acesso em: 09 abr. 2017.

MELLO. Celso Antônio Bandeira de. O conteúdo jurídico do princípio da igualdade. 3. ed. atual. 11 $1{ }^{a}$ tiragem. São Paulo: Malheiros, 2008.

ROCHA, Carmem Lúcia Antunes. O princípio da dignidade da pessoa humana e a exclusão social. Revista Interesse Público, São Paulo, n. 4, p. 23-49, 1999.

RODRIGUES, A. Construindo a perspectiva de gênero na legislação e nas políticas públicas. 2003. Disponível em: <http://www.maismulheresnopoderbrasil. com.br/estudos. php> Acesso em: 07 abr. 2017.

SARLET, Ingo Wolfgang. Direitos fundamentais sociais, mínimo existencial e direito privado. Revista de Direito do Consumidor, vol.61, jan./mar. 2007.

SCOTT, Joan. Gênero: uma categoria útil para a análise histórica. Recife: SOS Corpo, 1995.

SOARES, Barbara Musumeci. ILGENFRITZ, lara. Prisioneiras: vida e violência atrás das grades. Rio de Janeiro: Garamond, 2002 
SOARES, Ricardo Maurício Freire. Hermenêutica e Interpretação Jurídica. São Paulo: Saraiva, 2010b.

O princípio constitucional da dignidade humana: em busca do direito justo. São Paulo: Saraiva, 2010a.

SOARES, Vera. A longa Caminhada: a construção de Politicas Públicas para a igualdade entre homens e mulheres. In: Bittar, J. (org). Governos Estaduais: desafios e avanços. Editora Perseu Abramo, São Paulo, 2003.

SOUZA, Celina. Políticas Públicas: uma revisão da literatura. Sociologias, Porto Alegre, ano 8, no 16, jul/dez 2006, p. 20-45. 